\title{
Sustainability Entrepreneurship in Engineering
}

\author{
Amy Hsiao \\ Memorial University of Newfoundland \\ amy.hsiao@mun.ca
}

\begin{abstract}
Sustainability entrepreneurship is the use of innovative enterprise in a strategic manner to address a sustainability-related issue. By its operation, the process of sustainability entrepreneurship adds to the improvement of social, economic, and environmental concerns related to human quality of life. This work proposes that the distinction of sustainability entrepreneurship is having the business activity a characteristic of the innovation and making engineering or technology a critical component of the business solution. This work discusses how sustainability entrepreneurship can be introduced in undergraduate and graduate engineering curriculum, specifically through a materials science laboratory, engineering entrepreneurship, and engineering management experiences. Examples in this work demonstrate that sustainability entrepreneurship is a progression that begins with an understanding of the technical issues of sustainability as an engineering student, moves to the motivation, drive and identification of an opportunity that creates of a product or service valuable to an identified market, and finally creates a business that adds to the sustainability of life-supporting systems in the process.
\end{abstract}

Keywords: innovation, life cycle assessment, new product development, management.

\section{INTRODUCTION}

The topic of sustainability is a broadly defined one that spans many academic disciplines, from business, economics, and the social sciences, to science and engineering. This work focuses on applying integrated knowledge and interest in Materials Science and Engineering (MSE) and Engineering Management (EM) to inspire, define, and create innovation for sustainability in engineering students.

The paradigm of Materials Science and Engineering is inherently focused on sustainability, as opportunity for innovation and design is possible at each step of the Performance, Processing, Properties, and Microstructure cycle, shown in Figure 1. Synthetic fibers, the decreasing size of microchips, as examples, and mechanization, automation, and standardization have certainly changed the process yields and quality of manufactured products.

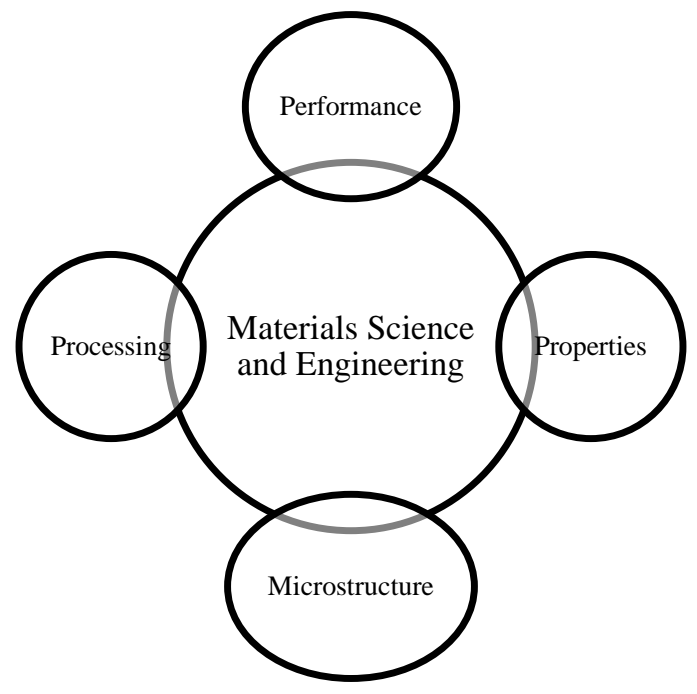

Fig. 1. Materials Paradigm

The forms that opportunities take are often specifically materials-related [6]:

- Use of raw materials

- Altering product dimensions

- Improving physical properties of products

- Improving product performance

- New production processes

- Scale and form of production

The forms that these opportunities take to impact sustainability can also be depicted by a life cycle assessment (LCA), in which technology innovation and engineering design is possible at each step, shown in Figure 2.

- Materials

- Manufacture

- Transport

- Use

- Disposal

- End of Life Potential 
The selection of materials, the manufacturing, assembly, and product design of these materials for applications (e.g. in energy, construction, defense, transportation, and communication/information), their transport, and their disposal, can be considered in which sustainability is not only a business objective but a way of doing business. Environmental impact as measured by energy costs, carbon dioxide $\mathrm{CO}_{2}$ footprint, and end-of-life potential (EoL) at each step can be optimized in new product development and as a vital component of entrepreneurial strategy.

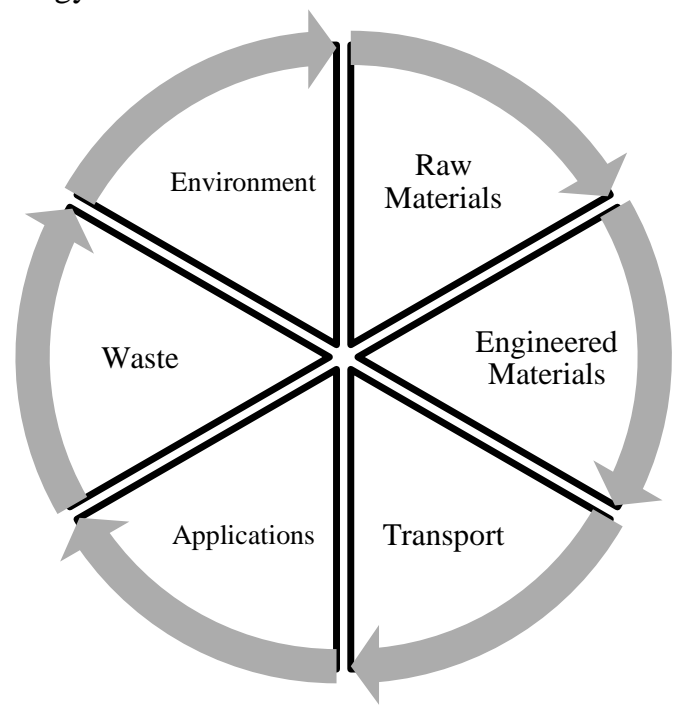

Fig. 2. Life Cycle Assessment

\section{SUSTAINABILITY FOR ENGINEERING MANAGERS}

The Master of Engineering Management (MEM) program in the Faculty of Engineering and Applied Science (FEAS) at Memorial University of Newfoundland (MUN) offers three graduate-level courses in which the topic of sustainability for technology and entrepreneurship are presented: (1) Engineering Management Topics and (2) Advanced Modeling and Quality Management, and (3) one course in which the topic can be applied or explored as a two-semester, twocredit MEM Research Project. Over the last four years, approximately a quarter of the MEM projects have focused on sustainability entrepreneurship in engineering.

\subsection{New Product Development}

One example from an MEM project focused on the evaluation of how the automotive industry in North America defined and conducted self-assessments on their sustainability. In this project, a novel sustainability indicators matrix, similar to a key performance matrix, was proposed by the MEM student, after collecting feedback from production line managers, on what components of sustainability were important to operations and business management.

Another MEM project researched the new venture feasibility of collecting and recycling stockpiles of old tires into construction-pavement materials in Newfoundland. The innovation in this case was not only the end-product but the strategy of addressing a locationbased opportunity that considered each step of the LCA and altered the end-of-life potential of automobile tires, as shown in Figure 3 [5].

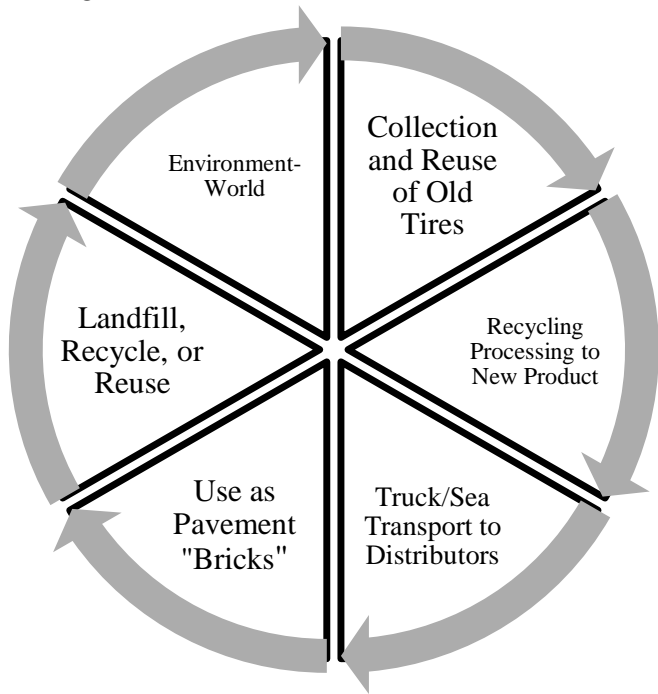

Fig. 3. Life Cycle Assessment of New Product from Reuse/Recycle of Car Tires Increasing End-of-Life Potential

Other similar examples of MEM projects have included the processing of biomass into fuels and the new venture creation of a plastics recycling entity in an underdeveloped country, using the model of the "CurbIt Curbside Recycling and Waste Management” Campaign in St. John's.

\subsection{Strategy}

The integration of the materials paradigm and the LCA model shown in Figures 1 and 2 can be compared with strategic business models and considered in what is defined as "strategic positioning" by M.E. Porter, i.e. "performing different activities from rivals' or performing similar activities in different ways" [5]. In addition, the engineering-entrepreneurial approach should in fact include sustainability in as many components of the business model of a technology-based enterprise, as shown in Figure 4. For example, a firm's mission, or mission statement, describes why it exists and what its business model is supposed to accomplish. If sustainability is a focused objective, then all following 
decisions will either reinforce or optimize this strategic differentiation. Similarly, a core competency is a resource or capability that serves as a source of a firm's competitive advantage, and if sustainability is incorporated as part of the venture's core competency, then all strategic decisions pertaining to assets, partnerships, pricing and customer engagement will either reinforce or optimize this [2]. These concepts are discussed in the MEM program and at the undergraduate level in an elective called Engineering Entrepreneurship.

\begin{tabular}{|l|l|l|l|}
\hline $\begin{array}{l}\text { Core } \\
\text { Strategy }\end{array}$ & Mission & Scope & Differentiation \\
\hline $\begin{array}{l}\text { Strategic } \\
\text { Resources }\end{array}$ & $\begin{array}{l}\text { Core } \\
\text { competences }\end{array}$ & Assets \\
\hline Networks & Suppliers & Other partnerships \\
\hline $\begin{array}{l}\text { Customer } \\
\text { Interface }\end{array}$ & Fulfillment & Support & Pricing \\
\hline
\end{tabular}

Fig. 4. Components of a Business Model [3]

\section{IDENTIFYING NEW VENTURE OPPORTUNITIES FOR SUSTAINABILITY}

It can be argued that emphasis on sustainability in entrepreneurship has been implicitly communicated over the last few years but not specifically made a focus in undergraduate curriculum. Sustainability has been discussed in the context of observing trends and external factors (economic, social, regulatory, technological, political and legal) for identifying new venture opportunities. In engineering curriculum, it is sometimes implied in design courses. In this work, a review of the undergraduate business ventures that have been researched and pursued by students over the last four years in the course Engineering Entrepreneurship in the FEAS at MUN reflect this "implied focus" in three areas:

- Sustainability as an opportunity

- Sustainability as a business model component

- Sustainability as a business objective, i.e. for a product or service

Figure 5 shows that approximately a quarter of these business ideas are related to one of the three points above. When categorized into the Ansoff Matrix of potential product-market growth, it can be seen that the majority of these new ventures ideas are new products in existing markets, or focused on new product development [1].

\begin{tabular}{|c|}
\hline $\begin{array}{c}\text { Product Development (new product or service in } \\
\text { existing market) }\end{array}$ \\
\hline • $\quad$ Small-scale, hydro-based energy generator \\
• Bluetooth technology to track people during \\
\hline
\end{tabular}

\begin{tabular}{|c|}
\hline $\begin{array}{ll} & \text { evacuation or emergency } \\
\text { - } & \text { Cursor manipulation via eye movement } \\
\text { - } & \text { Home energy monitoring system } \\
\text { - } & \text { Collapsible lobster trap } \\
\text { - } & \text { Electric motorcycle } \\
\text { - } & \text { Organic fertilizer (from chicken farm) } \\
\text { - } & \text { Downtown transport } \\
\text { - } & \text { Laundry service }\end{array}$ \\
\hline $\begin{array}{c}\text { Market development (present product/service in } \\
\text { new market }\end{array}$ \\
\hline $\begin{array}{l}\text { - "Green” construction waste management in NL } \\
\text { and removal from NL }\end{array}$ \\
\hline $\begin{array}{c}\text { Diversification (new product or service in new } \\
\text { market) }\end{array}$ \\
\hline - Home energy audits \\
\hline
\end{tabular}

Fig.5. Business Feasibility Ideas Focusing on Sustainability

For the focus on sustainability entrepreneurship to be more specifically emphasized in engineering curriculum, an increase in student exposure to sustainability as a theme or component in design, materials selection, and manufacturing would be significant.

\section{MATERIALS SUSTAINABILITY AND SUSTAINABILITY ENTREPRENEURSHIP}

In the Winter 2014 semester of Chemistry and Physics of Materials II, a new lab was implemented using materials selection software in which Term 8 Mechanical and Process Engineering students considered the issue of materials sustainability. The lab session introduced the students to the "Eco-Audit" element of the CES Edu-Pak package developed by Michael Ashby and his company, Granta Materials Inspiration and Design [4]. Students were then asked to take on the scenario of engineeringentrepreneurs who wanted to consider sustainability in the production of their products. The students were asked to prepare a technical memorandum discussing the life cycle assessment of a product of their choice. Students were to indicate four parameters to vary in the input (raw materials, manufacturing processes), transport, use, and disposal stages of the LCA. They were to consider the significance of each stage and the reuse-recycle-recover potential at end-of-life. The collection of selected products was:

- Kayak

- Bike helmet

- Bike frame

- Snowboard

- Hockey rink glass

- Bulletproof vest

- Keurig K-cups

- Wetsuit 
- Tennis racket

- Wind turbine

- Guitar strings

- Eyeglass frames

- Egg cartons

Figures 6 and 7 display abridged examples of students' reflection on the LCA parameters to evaluate materials sustainability.

"This memorandum is written to relay the findings of a product eco-design technique study. Research was done to find appropriate materials for a wetsuit, as well as realistic means of manufacture, transport and disposal.

For the basis of this study, an Eco-Audit report was conducted for wetsuits that could be utilized in Newfoundland waters, therefore the design needed to include thick materials, durable seals, and long sleeve and pant legs. The basis of this suit would need to be made of a material that can sustain extremely cold, salt-water conditions. Parameters including materials, manufacturing, transportation, and end-of-life processes were researched, and a wetsuit base-case model was created.

The base-case model of the wetsuit was fabricated from 5 $\mathrm{mm}$ thick neoprene for the body, with an estimated weight of $4 \mathrm{lbs}$. Silicon cuffs were then added with an estimated weight of $0.5 \mathrm{lbs}$. Other materials include a zipper made of polyoxymethylene (POM), liquid taping for seams made of natural rubber, and nylon lining for the inside of the suit. The total weight of material was estimated to be $5 \mathrm{lbs}$. The life span of the wetsuit was estimated to be 5 years and the end-of-life disposal for all components was landfill. It was assumed that the materials would be shipped by plane from Beijing to Vancouver. After being manufactured in Vancouver the wetsuits would be transported to Sydney, Nova Scotia by truck, and then taken by ferry from Sydney to Port Aux Basque.”

Fig.6. Example Sustainability Parameters for a Wetsuit

"Through research, the essential materials of a standard snowboard were determined to be its core, two fiberglass sheets, top and bottom sheets and its edges. These components resemble a structural composite or more specifically, a sandwich panel. For the purposes of this memo, the core piece was the only material altered. This is consistent with the marketplace, where the other materials remain relatively consistent from manufacturer to manufacturer. Three materials for the products core were analyzed: Carbon-Fiber-Reinforced Polymer (CFRP), pine wood and oak wood. It should be noted that the materials used for the fiberglass sheets, top and bottom sheets and edges were Glass-Fiber-Reinforced Polymer (GFRP), polyethylene and stainless steel.

One goal during the audit was to keep the process and product as local as possible, for this reason transportation was chosen as the next parameter. With exception to the polyethylene, used for the top and bottom sheets, all materials were sourced from vendors in Newfoundland and would be transported to the plant in Corner Brook via truck. The polyethylene would be transported from the closest manufacturer, based out of Lachine, Quebec. Two transportation methods are evaluated later in the report. The first method consists of the polyethylene being transported via ground and ferry while the other consists of predominantly airfreight"

Fig.7. Example Sustainability Parameters for a Snowboard

Figure 8 shows example work from students considering the $\mathrm{CO}_{2}$ footprint of a one-serving disposable coffee cup design using different cup materials and transport combinations. The students analyzed the most significant stages of the LCA for 100,000 non-recyclable, one-serve cups to be shipped from Massachusetts to St. John's (truck and sea) and showed that with a change in materials selection and type of processing, a significant reduction in the $\mathrm{CO}_{2}$ footprint of the product could be made.

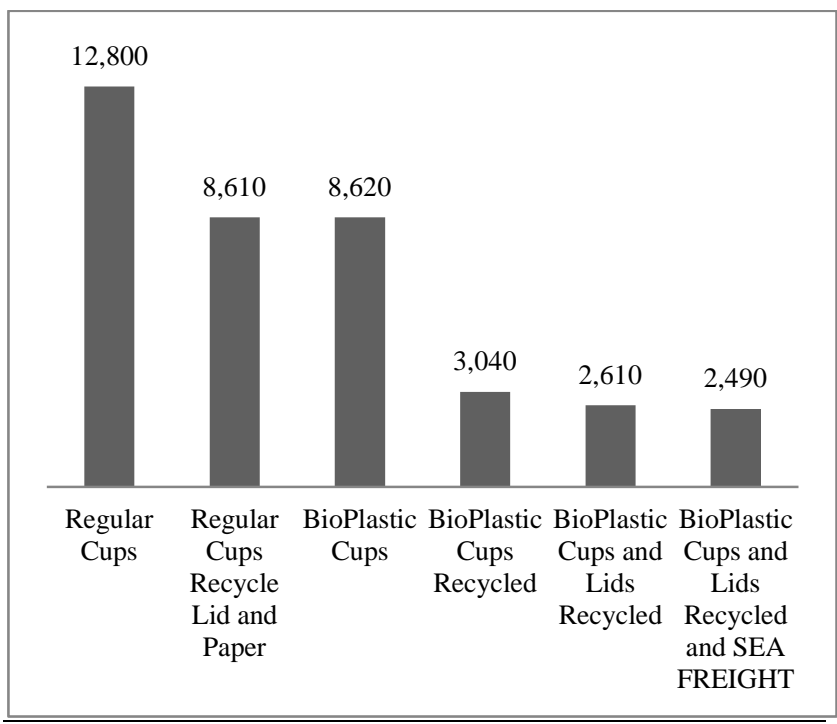

Fig.8. Comparison of $\mathrm{CO}_{2}$ Output in $\mathrm{Kg}$ by Different OneServing Cup Materials and Processing.

\section{DISCUSSION}

\subsection{Assessment of Impact and Effectiveness}

It can be argued that understanding and applying sustainability in engineering and entrepreneurship has more qualitative measures and a longer-term impact. In the projects discussed in this work, the quality of the outcomes was evaluated as ranging from satisfactory to excellent. In all cases, it was significantly clear that undergraduate students are interested in learning how to 
evaluate and apply sustainability and would like to see it as a theme or component in their engineering course. In terms of the Canadian Engineering Graduate Attributes, almost all of the attributes were addressed with the projects described in this work [3]:

- Problem analysis

- Investigation

- Design

- Use of Engineering Tools

- Teamwork

- Communication skills

- Professionalism

- Impact of Engineering on Society and the Environment

- Ethics and Equity

- Economics and Project Management

- Life-long learning

In addition, the author welcomes ideas and suggestions of assessment techniques that have been effective in quantifying and qualifying sustainability in engineering entrepreneurship.

\subsection{Sustainability in Service}

In this work, sustainability is discussed only in the sense of engineered materials and products. There are considerations for sustainability with service-based applications and new ventures, and these may be aligned with lean operations, optimization, and quality management. In the realm of this work, while not discussed, service-based sustainability is being further developed for the MEM course Advanced Modeling and Quality Management and has been the topic of a few MEM projects.

\subsection{Champion for Sustainability}

The dynamics and structure of an entrepreneurial endeavor are usually enforced and exemplified by the organization's champions. These champions may include the venture's founders, and just as it is important to have champions for organizational culture, knowledge sharing and management, and empowering leadership, it is critically important for entrepreneurial firms, as well as undergraduate and graduate Engineering departments, to have champions for sustainability. These champions practice "motivating and managing by walking around (MBWA)” and are ready to discuss the important aspects of sustainability.

\section{CONCLUSION}

This work presented sustainability entrepreneurship through the models of Materials Science and Engineering for engineered materials and engineered products, Engineering Management, Life Cycle Assessments, and Strategic Management. The educational activities to incorporate the topic of sustainability in engineering curriculum is just beginning, and sustainability entrepreneurship will be better defined and demonstrated in years to come. Sustainability entrepreneurship is a progression that begins with:

- an understanding of the technical issues of sustainability

- a motivation, drive and identification of an opportunity

- the creation of a product or service valuable to an identified market

- the formation of a business entity that aids in the preservation of life-supporting systems and the environment

The use of innovative enterprise in a strategic manner to address a sustainability-related issue, while contributing to the improvement of social, economic, and environmental concerns related to human quality of life, is certainly a concept for future engineers to embrace and consider. This work proposes that the essence of sustainability entrepreneurship is having the business activity a characteristic of the technology innovation and making engineering design a critical component of the business solution.

\section{References}

[1] H. Igor Ansoff, “Strategies for Diversification” Harvard Business Review, 1957, 113-124.

[2] Bruce R. Barringer and Duane Ireland, Entrepreneurship: Successfully Launching New Ventures (4/e). Prentice Hall, 2012, 592 pp.

[3] Engineers Canada, http://www.engineerscanada.ca/

[4] Granta Design Eco-Audit CES Edu-Pak, http://www.grantadesign.com/education/edupack/

[5] Michael E. Porter, "What is Strategy?” Harvard Business Review, November-December 1996, 61-78.

[6] Scott A. Shane, Finding Fertile Ground: Identifying Extraordinary Opportunities for New Venture. Pearson Prentice Hall, New Jersey, 2005, 256 pp. 